\title{
Net Anthropogenic Nitrogen Input (NANI) Evolution and Total Nitrogen (TN) Concentration Response in Zhaoshandu Water Source
}

\author{
A-long Li*, Hai-tao Chen*, Yuan-yuan Liu**, Lin Qiu* and Wen-chuan Wang*† \\ *School of Water Conservancy, North China University of Water Resources and Electric Power, Zhengzhou City Henan \\ Province, 450045, PR China \\ **Henan Huarun Engineering Design Co., Ltd., Zhengzhou City, Henan Province, 450045, PR China \\ †Corresponding Author: Wen-chuan Wang; liuyuan_hs@sina.com
}

\section{Nat. Env. \& Poll. Tech. Website: www.neptjournal.com \\ Received: $28-10-2019$ \\ Revised: $18-11-2019$ \\ Accepted: 16-01-2020 \\ Key Words: \\ Total nitrogen \\ NANI \\ Water source \\ Dynamic response \\ Regression model}

\begin{abstract}
The nitrogen concentration/flux of water is very sensitive to the response of Net Anthropogenic Nitrogen Inputs (NANI), but the research on the dynamic response of nitrogen concentration to NANI is still rarely reported. In this study, the source of Zhaoshandu water source in Zhejiang Province, China, was used as the research object. The dynamic response of total nitrogen (TN) concentration to NANI in the basin was quantitatively analysed from 2005 to 2014 . The results show that the NANI of the water source has a growing trend. It has increased by $6.73 \%$ in ten years. The average annual average of NANI is $85.76 \mathrm{~kg}\left(\mathrm{hm}^{2} \cdot \mathrm{a}^{-1}\right)$, which is 1.7 times the national average of 2009 . The average contribution rate of atmospheric nitrogen, chemical fertilizer nitrogen, food and feed nitrogen and crop fixed nitrogen is $40.98 \%, 34.06 \%, 20.25 \%$ and $4.7 \%$ respectively. The spatial difference of NANI is large, showing an increasing trend from the upstream mountainous area along the downstream. The sub-basin 2 is the key source of nitrogen pollution in this water source. NANI is the only independent variable of the TN concentration regression model with a variance interpretation rate of $55.4 \%$. In the future, it is necessary to reduce the nitrogen input intensity of nitrogen, food and feed for chemical fertilizers as the main target, and to achieve the goal of water quality improvement by reducing the NANI intensity in the basin.
\end{abstract}

\section{INTRODUCTION}

The increase of nitrogen concentration/flux in rivers not only endangers the ecosystem health of the water itself but also is one of the main causes of eutrophication of water bodies such as lake banks, estuaries and coasts (Chen et al. 2014, Zhang \& Chen 2014). How to effectively control nitrogen pollution in water has become one of the important scientific issues in the world. In the past two decades, the water body nitrogen pollution control strategy has experienced the development process from the end treatment, source control, process emission reduction, water ecological restoration to the comprehensive application of various control methods (Gao et al. 2016). However, in many regions/basins, despite the adoption of measures such as reducing fertilization and land-use conversion, the effectiveness of nitrogen pollution control is not optimistic (Stålnacke et al. 2003). One of the important reasons is that the response of river nitrogen pollution to human activities in the basin cannot be clarified. It can be seen that only by clarifying the dynamic response of water body nitrogen concentration/flux to human activities in the basin can provide a scientific basis for formulating an effective watershed nitrogen management strategy.
The existing methods rely mainly on the watershed model (SWAT, AGNPS, etc.) around the dynamic response of the nitrogen concentration/flux of the flowing water to the human activities in the basin. However, the watershed model is complex in structure, high in data requirements, difficult to calibrate and verify, and in application and promotion are greatly limited (Wang et al. 2016, Yang et al. 2007). In 1996, Howarth et al. (1996) pioneered the net anthropogenic nitrogen input (Net Anthropogenic Nitrogen Input, NANI) algorithm, which provides a new and effective means for assessing human input of reactive nitrogen. The NANI algorithm belongs to the quasi-material balance method, which mainly calculates the net anthropogenic nitrogen input of the region/basin based on conventional economic and social statistics. In general, net anthropogenic nitrogen inputs in a region include four inputs for fertilizer application of nitrogen, human food and animal feed nitrogen, crop fixed nitrogen and atmospheric sedimentation nitrogen, and NANI is the sum of these four inputs. Numerous studies have found that water nitrogen concentration/flux is very sensitive to the response of watershed NANI, and the quantitative relationship between the two can be expressed as linear or exponential (Chen et al. 2016, Han et al. 2009, Howarth et al. 2012). 
In summary, NANI has become an effective method to express the comprehensive impact of human activities on the nitrogen cycle process, providing a new way to study the response of water nitrogen concentration/flux to human activities. However, studies on the dynamic response of nitrogen concentration in water sources to NANI are still rarely reported in China (Zhang \& Chen 2014). Therefore, it is of great practical significance to study the dynamic response of nitrogen concentration in the water source to NANI. In this study, the Zhaoshandu water source in Zhejiang Province, China, was used as the research object. From 2005 to 2014, the regression model of TN concentration on NANI and main natural factors was established to promote nitrogen management and promote water nitrogen control in the basin.

\section{MATERIALS AND METHODS}

\section{Study Area}

The study area is located in the upper reaches of Feiyun River in Zhejiang Province, China. The river originates from the mountainous area of southwest Zhejiang, with a total length of $203 \mathrm{~km}$ and a drainage area of $3252 \mathrm{~km}^{2}$. The main water conservancy project in the water source of Zhaoshandu includes a multi-year regulation reservoir and a water diversion project. It has functions of water supply, power generation and flood control, and is one of the important drinking water sources in southern Zhejiang (Fig. 1). The normal water storage level of the upstream multi-year regulation reservoir is $142 \mathrm{~m}$, with a total storage capacity of 1.824 billion $\mathrm{m}^{3}$. The entire water source basin area is $2280 \mathrm{~km}^{2}$, and the upper control basin area above the upstream reservoir dam site is $1529 \mathrm{~km}^{2}$ (Fig. 1). Affected by the subtropical monsoon climate, the average annual precipitation is $1876 \mathrm{~mm}$, and the average annual precipitation is 149 days. The precipitation is unevenly distributed during the year, and the rainfall is concentrated from April to September, accounting for $75 \%$ of the whole year. The average elevation of the whole basin is $573 \mathrm{~m}$, the soil is mainly red soil, and the rest are yellow soil, purple soil, coarse soil and paddy soil. The land-use type is mainly forest land, accounting for $71 \%$ of the total area, followed by cultivated land, accounting for about $20 \%$.

\section{Data Source}

In this study, a hydrological water quality monitoring station was set up in the water diversion project (before the anti-regulation reservoir dam), and seven rainfall observation stations were set up in the basin. There are multiple water quality monitoring stations in the basin, and the frequency of water quality monitoring is once a month. The monthly TN concentration data from 2005 to 2014 is provided by the local environmental protection department. The daily flow and water level data for the same period are provided by the local water conservancy department. The SWAT model is used to divide the basin boundaries above the counter-regulation reservoir. The basin boundary covers the large area of two county-level administrative regions and a small area of two county-level administrative regions (Fig. 1). The main data source for calculating NANI is the calendar yearbook of the four county-level administrative regions. After calculating the NANI of the county-level administrative region, the watershed boundary and the administrative boundary are superimposed and analysed using ArcGIS 10.2.

\section{NANI Calculation}

Referring to previous studies, NANI was obtained by summing up atmospheric precipitation nitrogen, nitrogen fertilizer, crop fixed nitrogen, and food and feed nitrogen (Chen et al. 2016, Gao et al. 2016). The calculation formula is expressed as follows:

NANI $=$ Atmospheric N+ Fertilizer N+Crop fixed N+ Food $\&$ feed $\mathrm{N}$

Where,

1. Atmospheric N. The main forms of atmospheric

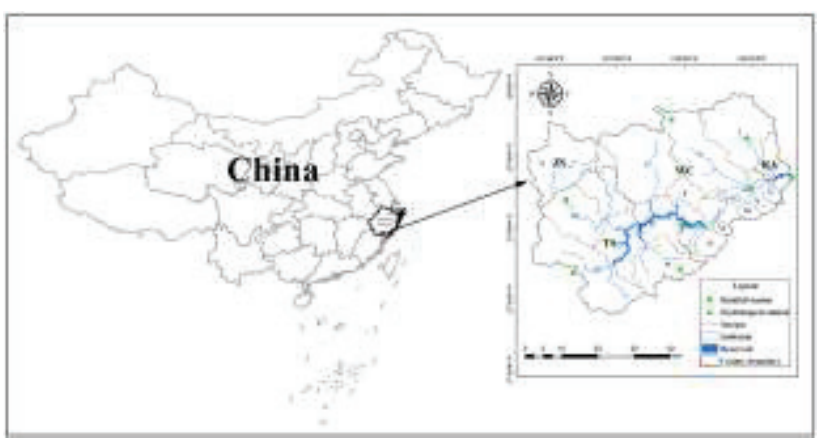

Fig.1: Geographic location of the study area. 
precipitation nitrogen are $\mathrm{NH}_{\mathrm{y}}, \mathrm{NO}_{\mathrm{y}}$ and organic nitrogen. In the NANI model, only atmospheric precipitation nitrogen in the form of $\mathrm{NO}_{\mathrm{y}}$ is considered, including dry deposition and wet deposition (Smedberg et al. 2012). Atmospheric nitrogen refers to the research results of (Liu et al. 2013) on the southeastern region of China and (Wang et al. 2015) on the research results of the Taihu Lake Basin in China. The values of different years are calculated using the average of two studies.

2. Fertilizer application of nitrogen. The statistics of nitrogen fertilizer in the statistical yearbook are divided into pure nitrogen fertilizer and nitrogen fertilizer in compound fertilizer. According to the application amount, the nitrogen content is reduced by the content and molecular weight, and the specific nitrogen content is $46 \%$ of urea, $35 \%$ of ammonium nitrate, and $12.8 \%$ of compound fertilizer. The amount of nitrogen fertilizer applied is obtained by adding the nitrogen content of each type of fertilizer.

3. Fixed nitrogen for crops. The fixed nitrogen of crops is calculated from the crop planting area and the ability of nitrogen fixation rate per unit area of crops. In this study, the planting area of nitrogen-fixing crops was obtained from the statistical yearbook. According to the characteristics of Zhaoshandu water source and the research results of the Taihu Lake Basin, the nitrogen fixation rate of crops was as follows: green fertilizer was $150 \mathrm{~kg} \cdot\left(\mathrm{hm}^{2} \cdot \mathrm{a}\right)^{-1}$, for legume crop was $64 \mathrm{~kg} \cdot\left(\mathrm{hm}^{2} \cdot \mathrm{a}\right)^{-1}$; $45 \mathrm{~kg} \cdot\left(\mathrm{hm}^{2} \cdot \mathrm{a}\right)^{-1}$ for paddy fields and $15 \mathrm{~kg} \cdot\left(\mathrm{hm}^{2} \cdot \mathrm{a}\right)^{-1}$ for other dry land and gardens (Ti et al. 2012, Yan et al. 2011).

4. Food and feed nitrogen. Food and feed nitrogen is the amount of nitrogen consumed by human food and animal feed minus the amount of nitrogen in animal products for human consumption and the amount of nitrogen harvested by crops. Nitrogen in human food is calculated by multiplying the per capita consumption of nitrogen by the population. The nitrogen content of the animal's consumption of food is obtained by multiplying the amount of nitrogen consumed by the individual of the livestock during the year. The nitrogen content of animal products is obtained by multiplying the amount of livestock in the year by the nitrogen content of the animal product, and food that cannot be ingested due to deterioration and other reasons is calculated at $10 \%$ of the total production. The nitrogen consumption of human and livestock and the nitrogen content of animal products refer to the research results of Han et al. (2011), as given in Table 1. Taking into account the number of years of stocking and the number of livestock in the statistical yearbook, the amount of livestock in the year is used to calculate the amount of livestock. The calculation method refers to Smedberg et al. (2012).

The amount of nitrogen harvested by the crop is obtained by multiplying the yield of the various crops in the statistical yearbook by the nitrogen content of the crop. The nitrogen content of various crops is taken from the Chinese Food Ingredients Table (Wang 2002). The nitrogen content of various crops calculated in this study is given in Table 2 . The vegetables are calculated according to the nitrogen content of the main ingredient cabbage. Food that cannot be ingested due to deterioration and other reasons is calculated at $10 \%$ of total production.

\section{RESULTS AND DISCUSSION}

\section{Temporal Change of NANI}

According to the calculation, the average NANI of Zhaoshandu water source was $85.76 \mathrm{~kg} \cdot\left(\mathrm{hm}^{2} \cdot \mathrm{a}\right)^{-1}$ from 2005 to 2014, and the average contribution rates of atmospheric nitrogen, fertilizer nitrogen, food and feed nitrogen and crop-fixed nitrogen, were $40.98 \%, 34.06 \%, 20.25 \%$, and $4.7 \%$, respectively. Atmospheric sedimentation nitrogen and fertilizer nitrogen are the main inputs of NANI in this water source, with a total contribution rate of $75.04 \%$, which is similar to the calculation results in China such as Jiaojiang River Basin (Chen et al. 2014), Haihe River Basin (Chen et al. 2016) and Poyang Lake Basin (Gao et al. 2016). According

Table 1: Nitrogen consumption and excretion of human or individual animals.

\begin{tabular}{|llll|}
\hline Species & Consumption of nitrogen $\left(\mathrm{kg} \cdot \mathrm{a}^{-1}\right)$ & Excretion of nitrogen $\left(\mathrm{kg} . \mathrm{a}^{-1}\right)$ & Animal product nitrogen content $\left(\mathrm{kg} \cdot \mathrm{a}^{-1}\right)$ \\
\hline Pig & 16.68 & 11.51 & 5.17 \\
Cattle & 54.82 & 48.78 & 6.03 \\
Sheep & 6.85 & 5.75 & 1.1 \\
Chicken & 0.57 & 0.37 & 0.2 \\
Duck & 0.63 & 0.41 & 0.22 \\
Human & 4.39 & 4.39 & 0.00 \\
\hline
\end{tabular}


Table 2: Nitrogen content of major agricultural products.

\begin{tabular}{|ll|}
\hline Agricultural products & Nitrogen content $\left(\mathrm{kg} \cdot \mathrm{kg}^{-1}\right)$ \\
\hline Cereals & 0.01184 \\
Wheat & 0.0192 \\
Soybean & 0.0562 \\
Broad bean & 0.0406 \\
Sweet potato & 0.0018 \\
Rapeseed & 0.0456 \\
Vegetables & 0.0032 \\
Tangerine & 0.0014 \\
\hline
\end{tabular}

to the results of (Han et al. 2014), the average NANI in China in 2009 was $50.13 \mathrm{~kg} \cdot\left(\mathrm{hm}^{2} \cdot \mathrm{a}\right)^{-1}$, and the average NANI in Zhaoshandu water source from 2005 to 2014 was 1.7 times the national average, for a water source. In other words, the NANI intensity is at a high level. During the period from 2005 to 2014, NANI has a growing trend, increasing from $81.98 \mathrm{~kg} \cdot\left(\mathrm{hm}^{2} \cdot \mathrm{a}\right)^{-1}$ in 2005 to $87.50 \mathrm{~kg} \cdot\left(\mathrm{hm}^{2} \cdot \mathrm{a}\right)^{-1}$ in 2014 and an increase of $6.73 \%$ in ten years (Fig. 2).

It can be seen from Fig. 2 that the dynamic trends of different inputs of NANI in Zhaoshandu water source are different. Atmospheric sedimentation nitrogen has a linear increasing trend, which is based on the research results of southeastern China (Han et al. 2014) and Taihu Lake Basin (Wang et al. 2015), and also assumes that the atmospheric sedimentation nitrogen of the water source has a linear increase year by year. Nitrogen application by chemical fertilizers also has an increasing trend, especially after 2009 , due to the increase in the intensity of local agricultural production activities. Food and feed nitrogen was relatively stable before 2010 and has declined year after year since 2010. Since 2009, the local management department has carried out water and soil conservation and ecological clean small watershed construction projects in water sources, which has achieved remarkable results. Crop fixed nitrogen remained stable during the study period because the area under which nitrogen-fixed crops were grown did not change much during the 10 years. Since fertilizer application of nitrogen and atmospheric subsidence nitrogen account for most of NANI, the trend of these two inputs determines the trend of NANI.

\section{Spatial Change of NANI}

In this study, the NANI of the water source basin was calculated at the county-level administrative regional scale. However, the spatial scale of the county-level administrative district was too large. This study uses the spatial analysis function of Arcgis10.2 to distribute NANI and its components to each sub-basin according to the area weighting method. The spatial distribution of the NANI and its multi-year averages in the 17 sub-basins of the Zhaoshandu water source is shown in Fig. 3. It can be seen from Fig. 3a that the spatial difference of NANI intensity in each sub-basin is larger, showing a trend of increasing from the upstream mountainous area to downstream. The areas with the largest and smallest NANI intensity were sub-basins 2 and 11 with $135.26 \mathrm{~kg} \cdot\left(\mathrm{hm}^{2} \cdot \mathrm{a}\right)^{-1}$ and $72.4 \mathrm{~kg} \cdot\left(\mathrm{hm}^{2} \cdot \mathrm{a}\right)^{-1}$, respectively. The sub-basin 2 is located at the exit of the water source, mainly in the RA. The NANI intensity was 1.87 times of sub-basin 11. The fertilizer nitrogen, food and feed nitrogen are 3.21 times and 2.17 times respectively of sub-basin 11 . For atmospheric deposition of nitrogen, this study assumes

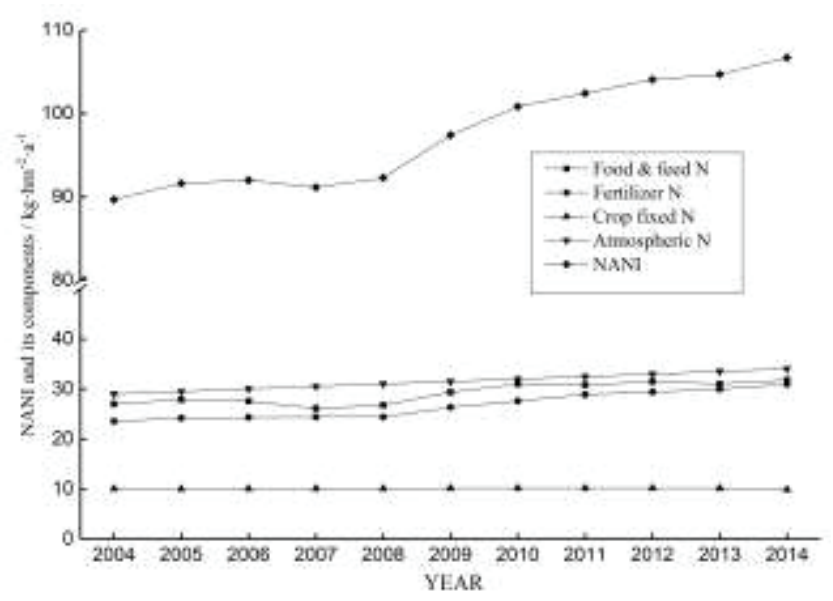

Fig. 2: Dynamic changes of NANI and its inputs from 2005 to 2014. 
that the spatial distribution throughout the water source is uniform and the intensity of each administrative area is the same (Fig. 3e). The fixed nitrogen of crops mainly depends on the planting area of nitrogen-fixing crops. The application of nitrogen in fertilizers mainly depends on the planting area of crops and the fertilization intensity. The food and feed nitrogen mainly depend on the population density and the scale of livestock and poultry breeding, so there is a certain spatial difference. In general, there are some differences in the level of economic and social development of different administrative units. After spatial analysis, the nitrogen input values of each sub-basin were obtained, which results in the spatial heterogeneity of NANI. The occurrence of nonpoint source pollutants (NPS) is affected by many factors such as soil, topography, climate, hydrology, land use and management. The spatial difference is very significant. The pollutants output by a few landscape units often account for the majority of the pollution load of the entire basin and thus become a key source of NPS. Since 2012, while continuing to promote the comprehensive improvement of livestock and poultry breeding, the local government has vigorously promoted the transformation of rural water sources and cross-regional pooling, minimizing the population of primary and secondary water source protection areas, and minimizing the pollution of storage, thereby achieving the purpose of reducing the total amount of pollutants entering the reservoir. On this basis, spatial identification of key source areas of NPS is significant for the control and management of NPS in the basin. For the water source, sub-basin 2 is not only strong in NANI, but also 2.71 times of the national average $\left(50.13 \mathrm{~kg} \cdot\left(\mathrm{hm}^{2} \cdot \mathrm{a}\right)^{-1}\right)$, and it is at the water intake, which has the greatest potential risk to water quality. Therefore, it is a key source of nitrogen pollution in the water source, and it is necessary to take targeted source control measures.

\section{Net Anthropogenic Nitrogen Input and TN Concentration Response}

It is important to identify the dynamic changes of water quality time series and reveal the dynamic response of water quality to pollution sources, which has important practical significance for water quality protection (Zhang \& Chen 2014). According to the long-term nitrogen input data and water nitrogen concentration, the response relationship between water nitrogen concentration and watershed NANI is constructed by multiple linear regression model, which can identify the driving and contribution of human activities to the change of water nitrogen concentration (Gao et al. 2016). To reveal the quantitative relationship between TN concentration in Zhaoshandu water source and NANI and related hydrological and meteorological factors, this study used the annual average $\mathrm{TN}$ concentration of the diversion project during 2005-2014 as the dependent variable, with the whole basin NANI. The annual average precipitation of the whole basin, the annual average temperature of the whole basin and the annual average water level of the diversion project are independent variables, and a multiple linear regression model was established. After stepwise regression analysis, the variables with significant influence are retained, and the variables with insignificant influence are eliminated. The final model expression is as follows:

$$
\begin{gathered}
{[\mathrm{TN}]=0.04 \times[\mathrm{NANI}]-2.888} \\
\left(\mathrm{R}^{2}=0.554, \mathrm{p}=0.014\right)
\end{gathered}
$$

Where, $[\mathrm{TN}]$ is the annual average $\mathrm{TN}$ concentration of water $\left(\mathrm{mg} \cdot \mathrm{L}^{-1}\right)$, and [NANI] is the annual average NANI intensity of the whole basin $\left(\mathrm{kg} \cdot\left(\mathrm{hm}^{2} \cdot \mathrm{a}\right)^{-1}\right)$.

For the TN concentration model of the Zhaoshandu water source, the only independent variable is NANI, which is

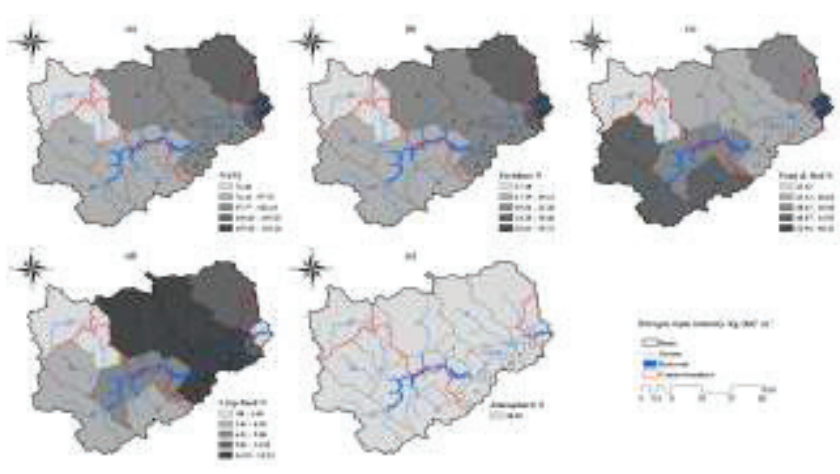

Fig. 3: Spatial distribution of NANI. 
consistent with Gao et al. (2016) for the regression model of Poyang Lake TN concentration to NANI. In general, factors affecting the nitrogen concentration of water bodies may be affected by factors such as hydrometeorology in addition to the intensity of NANI. However, NANI's time scale is years, and many basins lack long-term water quality data, resulting in a small sample size of the regression model, which may not be able to identify the impact of hydrological and meteorological factors. The coefficient of determination of the regression model of the Zhaoshandu water source reached $0.554(\mathrm{p}=0.014)$, indicating that the TN concentration of the water source responded strongly to NANI. In recent years, with the continuous advancement of the "five-water joint governance" in Zhejiang Province, the local government has fully implemented the "five major" projects for water source protection, including domestic sewage treatment, domestic garbage treatment, livestock and poultry pollution control, and major tributary ecological protection. "Five major" project construction of water source protection include such as repair, automatic online monitoring of water quality and early warning system. The interpretation rate of the variance of NANI to TN concentration reached $55.4 \%$, indicating that human activities are the main driving force for the change of nitrogen concentration in the water source of Zhaoshandu watershed, and also pointed out the direction for future nitrogen management of water source. The atmospheric nitrogen input intensity is large, and it is difficult to control. It is difficult to avoid nitrogen fixation in crops, but the input intensity is not large. In the future management of watershed nitrogen, it is necessary to reduce the input of food and feed nitrogen and fertilizers nitrogen as the main target. By reducing the NANI intensity in the basin, it is expected to achieve the goal of water quality improvement.

\section{CONCLUSIONS}

1) During the period from 2005 to 2014 , the average NANI of the Zhaoshandu water source was $84.80 \mathrm{~kg} \cdot\left(\mathrm{hm}^{2} \cdot \mathrm{a}\right)^{-1}$, which is 1.7 times the national average in China. The atmospheric nitrogen, fertilizer application of nitrogen, food and feed nitrogen and the average contribution rates of fixed nitrogen in crops were $40.98 \%, 34.06 \%$, $20.25 \%$ and $4.7 \%$, respectively. The water source NANI has a growing trend, increasing by $6.73 \%$ in ten years.

2) The spatial difference of NANI in each sub-basin is large, showing a trend of increasing from the upstream mountainous area along the downstream. The strength of NANI in sub-basin 2 is up to 2.71 times the national average in China, and it is at the water intake, which has the greatest potential risk to water quality. It is the key source of nitrogen pollution in this water source and needs to adopt targeted source control measures.

3) The main influencing factor of the annual average concentration of TN in Zhaoshandu water source area is NANI, and the interpretation rate of the variance of $\mathrm{TN}$ concentration reaches $55.4 \%$. In future watershed nitrogen management work, nitrogen, food and feed nitrogen input should be reduced. Strength is the main goal, and the goal of water quality improvement is achieved by reducing the NANI intensity of the basin.

\section{ACKNOWLEDGEMENTS}

This research was supported by the Key Scientific and Technological Research Projects in Henan Province (Grants No. 192102110199).

\section{REFERENCES}

Chen, D. J., Huang, H., Hu, M. P. and Dahlgren, R. A. 2014. Influence of lag effect, soil release, and climate change on watershed anthropogenic nitrogen inputs and riverine export dynamics. J. Environmental Science \& Technology, 48(10): 5683-90.

Chen, Y., Gao, W., Wang, D., Liu, Y., Wu, Y. Y. and Guo, H. C. 2016. Net nitrogen input and river response characteristics of human activities in water-deficient areas: taking the Haihe River Basin as an example. J. Journal of Environmental Science, 36(10): 3600-3606.

Gao, W., Gao, B., Yan, C. A. and Liu, Y. 2016. Anthropogenic nitrogen and phosphorus input evolution and lake water environment response in Poyang Lake Basin. J. Journal of Environmental Science, 36(9): 3137-3145.

Han, H., Allan, J. D. and Donald, S. 2009. Influence of climate and human activities on the relationship between watershed nitrogen input and river export. J. Environmental Science \& Technology, 43(6): 1916.

Han, Y. G., Fan, Y. T., Yang, P. L., Wang, X. X., Wang, Y., Tian, J., Lei, X. and Wang, C. 2014. Net anthropogenic nitrogen inputs (NANI) index application in Mainland China. J. Geofisica International, 213(1): 87-94.

Han, Y. G., Li, X. Y., Nan, Z. and Li, B. 2011. Study on nitrogen accumulation of human activities in Beijing area from 2003 to 2007. J. Environmental Science, 32(6): 1537-1545.

Howarth, R., Swaney, D., Billen, G., Garnier, J., Hong, B., Humborg, C., Johnes, P., Mörth, C. M. and Marino, R. 2012. Nitrogen fluxes from the landscape are controlled by net anthropogenic nitrogen inputs and by climate. J. Frontiers in Ecology \& the Environment, 10(1): 37-43.

Howarth, R. W., Billen, G., Swaney, D., Townsend, A., Jaworski, N., Lajtha, K., Downing, J. A., Elmgren, R., Caraco, N. and Jordan, T. 1996. Regional nitrogen budgets and riverine N \& P fluxes for the drainages to the North Atlantic Ocean: Natural and human influences. J. Biogeochemistry, 35(1): 75-139.

Liu, X. J., Zhang, Y., Han, W. X., Tang, A., Shen, J. L., Cui, Z. L., Vitousek, P., Erisman, J. W., Keith, G. and Peter, C. 2013. Enhanced nitrogen deposition over China. J. Nature, 494(7438): 459-462.

Smedberg, E., Eriksson, H. H., Swaney, D. P., Howarth, R. W., Mirth, C. M., Humborg, C., Hong, B. and Bouraoui, F. 2012. Evaluating regional variation of net anthropogenic nitrogen and phosphorus inputs (NANI/ NAPI), major drivers, nutrient retention pattern and management implications in the multinational areas of Baltic Sea basin. J. Ecological Modelling, 227: 117-135.

Stålnacke, P., Grimvall, A., Libiseller, C., Laznik, M. and Kokorite, L. 2003. Trends in nutrient concentrations in Latvian rivers and the response to 
the dramatic change in agriculture. J. Journal of Hydrology, 283(1): 184-205.

Ti, C. P., Pan, J. J., Xia, Y. Q. and Yan, X. Y. 2012. A nitrogen budget of mainland China with spatial and temporal variation. J. Biogeochemistry, 108(1/3): 381-394.

Wang, G. Y. 2002. Chinese Food Ingredient List 2002.

Wang, X. C. Jin, M. J. and Feng, H. D. 2016. Progress in the application of distributed hydrological model SWAT in non-point source pollution research. J. Journal of Agricultural Science Yanbian University, 38(3): 271-276.

Wang, Y., Liu, N. K. and Wang, J. F. 2015. Study on atmospheric deposition of nitrogen and phosphorus in Taihu Lake Basin. J. Environmental Science and Management, 40(5): 103-105.

Yan, X. Y., Cai, Z. C., Rong, Y., Ti, C. P., Xia, Y. Q., Li, F. Y., Wang, J. Q. and Ma, A. J. 2011. Nitrogen budget and riverine nitrogen output in a rice paddy dominated agricultural watershed in eastern China. J. Biogeochemistry, 106(3): 489-501.

Yang, J., Reichert, P., Karim, C. and Yang, H. 2007. Hydrological modelling of the Chaohe Basin in China: Statistical model formulation and Bayesian inference. J. Journal of Hydrology, 340(3): 167-182.

Zhang, B. F. and Chen, D. J. 2014. Dynamic response of nitrate flux in a typical river in Zhejiang Province to net human nitrogen input from 1980 to 2010. J. Environmental Science, (8): 2911-2919. 